Article

\title{
Experimental Investigation on the Residual Stresses in a Thick Joint with a Partial Repair Weld Using Multiple-Cut Contour Method
}

\author{
Chuan Liu ${ }^{1, *(\mathbb{D})}$, Chunjing Wang ${ }^{1}$, Xiaohua Cheng ${ }^{2}$, Yi Yan ${ }^{1}$, Jiawei Yang ${ }^{1}$ and Yuhang Guo ${ }^{1}$ \\ 1 Provincial Key Lab of Advanced Welding Technology, Jiangsu University of Science and Technology, \\ Zhenjiang 212003, China; chunjing1994@126.com (C.W.); yiyan_lengduo@126.com (Y.Y.); \\ young10402@163.com (J.Y.); guoyuhang@just.edu.cn (Y.G.) \\ 2 China Nuclear Industry Huaxing Construction Company Limited, Nanjing 21000, China; \\ chxh9361@aliyun.com \\ * Correspondence: chuanliu@just.edu.cn; Tel.: +86-511-844-01184
}

Received: 7 April 2018; Accepted: 19 April 2018; Published: 20 April 2018

\begin{abstract}
The stress distributions in a thick welded specimen with a partial repair weld were measured with the three-cut contour method. The longitudinal stress maps in the original weld and the repair weld were obtained and the transverse stress map at the weld centerline in the original weld was acquired. The difference between the longitudinal stress in the partial repair weld and that in the original weld was investigated. Results show that the longitudinal stress increases significantly within the entire repair region with a peak tensile longitudinal stress close to the yield strength of weld material; and the longitudinal stress in the region above the repair weld decreases distinctly after repair; the introduction of the partial repair weld does not affect the stress distribution trend in the original weld (whether it is beyond or above the repair weld), and it has a slight effect on the tensile stress distribution width in the repair region.
\end{abstract}

Keywords: repair weld; residual stress; multiple-cut contour method; thick welded specimen; superposition

\section{Introduction}

Welding residual stresses, developed due to localized heating and non-uniform cooling accompanied with steep thermal gradients that arise in the weld zone, have been known as one of the most critical factors in weldments. The detrimental effects of welding residual stresses on the structural integrity, fatigue performance, service security, and remaining life of the welded structures are significant [1]. Welded components are usually repaired during manufacture or in-service after removal of defects or degraded material. Repair welds can influence the magnitude and distribution of the as-welded residual stresses in the weldments. The stress distribution and variation in repair welds have attracted much attention during recent decades. For example, Dong et al. [2,3] found that the weld repairs typically increase the magnitude of transverse residual stresses along the repair compared with the original weld and that the shorter the repair length the greater the increase in the transverse stress. Recently, Song and Dong [4] suggested that a weld repair should be designed as long as possible, as narrow as possible, and as shallow as possible.

Experimental evaluation is the essential method to investigate the welding residual stress and also provide sufficient information to verify the numerical simulation model. The methods to experimentally determine the surface stress, such as the hole-drilling method and X-ray diffraction (XRD) method, are available to measure the welding stress before and after repair. For example, Zeinoddini et al. [5] measured the residual stresses in single/double and partial/full repair welds in 
offshore pipelines with the hole-drilling method. It was found that the repetition of repair welding in same area influenced the stress magnitude and distribution especially in areas close to the weld centerline. Veiga et al. [6] investigated the influence of the repair procedure on the evolution of residual stress distribution in $11 \mathrm{~mm}$-thick butt welds with the XRD method. They found that the repair welds caused a decrease in magnitude of the initial longitudinal residual welding stresses, and an increase of the transverse residual stress magnitude in tension at points within the repair length, and in compression at points outside the repair length.

The repair weld needs to fully or partially remove the initial weld material, the internal stress distribution after repair could be much different from the original condition and the measurement of surface stress is not enough to investigate internal stress variation. Therefore, the methods with the ability of measuring the through-thickness stress, such as the deep-hole method and neutron diffraction (ND) method, are adopted to evaluate the through-thickness stress variation before and after repair. For example, George and Smith [7] measured the through-thickness residual stress profiles before and after introducing deep and shallow part-circumferential weld repairs into a $37 \mathrm{~mm}$ thick stainless steel cylinder using the deep-hole drilling method. They found that the membrane and bending components of the in-plane residual stresses were generally increased when weld repairs were introduced. Bouchard et al. [8] investigated the residual stresses in a stainless steel pipe girth weld containing long and short repairs with the deep-hole method, ND method, and surface hole-drill technique. It was indicated that the residual stresses at mid-length of the heat affected zone of the short repair were found to be higher than those in the long repair.

The research results obtained by Dong et al. [2], Song and Dong [4], and Bouchard et al. [8] demonstrated that the residual stresses in repair welds typically exhibit strong three-dimensional (3D) features, depending on repair geometries. Therefore, a 2D or 3D residual stress map is more useful to understand the stress distribution and variation in repair welds. The deep-hole method can only get the through-thickness stress at limited locations. Diffraction techniques might seem preferable to get the 2D or 3D stress distributions within the sample without affecting the integrity of the specimen under investigation. However, a number of limitations inherent to both neutron and synchrotron diffraction techniques exist, including the limited specimen thickness and grain size, high cost, requirement of stress-free reference specimens, sensitivity to microstructure, and equipment not being readily available [9].

The contour method (CM) is a promising relaxation method to get the full 2D stress map on a plane of interest [10]. In addition, it is insensitive to microstructure variation (weld/parent metal), the sample thickness, and the required equipment is readily available [9]. The CM has been used to achieve full 2D stress maps in specimens with different welding methods including arc welding [11], variable-polarity plasma-arc welding [12], friction welding [13-16], and electron beam welding [17]. Comparisons with the ND measurements indicate that the contour method can accurately measure through thickness residual stresses [18-20]. With the principle of superposition, the CM has been developed to measure the biaxial stress distribution on a cross-section plane by integrating other stress measurement methods, such as the slitting method [21] and the XRD method [22,23]. Furthermore, the $\mathrm{CM}$ can be also used to measure the multiple residual stress components by multiple cuts [24].

In the present study, the contour method with multiple cuts was adopted to measure the residual stresses in a thick butt-welded joint with a partial repair weld, the residual stress maps on three cut planes were obtained and the internal stress in repair region were compared with that within the initial weld. The XRD method was also used to measure the surface stress distribution.

\section{Welding Experiment}

Two plates with the dimensions of $200 \times 200 \times 50 \mathrm{~mm}$ were butt-welded together with the gas metal arc welding (GMAW). The groove configuration and the final dimensions of the specimen are shown in Figure 1a,b. The $1.2 \mathrm{~mm}$-diameter flux-cored welding wire (CHT711HR) was used and the $\mathrm{CO}_{2}$ shielding gas was employed during welding. The base metal is Q345D steel with a yield strength 
of $392 \mathrm{MPa}$, and the yield strength of the weld metal is $543 \mathrm{MPa}$. The chemical compositions of the base metal and the weld metal are shown in Table 1.

Table 1. Chemical compositions of the base metal and weld metal (wt \%).

\begin{tabular}{cccccccc}
\hline \multirow{2}{*}{ Base/Weld Metal } & \multicolumn{7}{c}{ Chemical Composition } \\
\cline { 2 - 8 } & $\mathbf{C}$ & Mn & Si & S & $\mathbf{P}$ & $\mathbf{C r}$ & Fe \\
\hline Q345D (base metal) & 0.17 & 1.52 & 0.22 & 0.009 & 0.023 & - & Balance \\
Weld metal & 0.069 & 1.30 & 0.36 & 0.006 & 0.019 & 0.037 & Balance \\
\hline
\end{tabular}

There are 22 passes used to finish the initial weld. After finishing pass 6, the root pass (pass 1) was removed by the carbon arc gouging, and then the subsequent passes were filled. The welding sequence is shown in Figure 1c. The preheating temperature and the interpass temperature were $60{ }^{\circ} \mathrm{C}$. After welding, part of the weld was removed from the bottom surface by carbon arc gouging to create a localized excavation and the surfaces of the excavation were ground, then the excavation was re-welded (the repair weld was introduced). The location of the repair region is illustrated in Figure $1 \mathrm{~b}$. The maximum depth of the excavation is approximate $27 \mathrm{~mm}$, the maximum width is about $27 \mathrm{~mm}$, and the length of the repair weld is $180 \mathrm{~mm}$. Total 14 passes were adopted to finish the repair weld. The welding sequence and the dimensions of the repair weld are shown in Figure 2. The welding parameters employed for the original weld and subsequent repair are shown in Table 2.
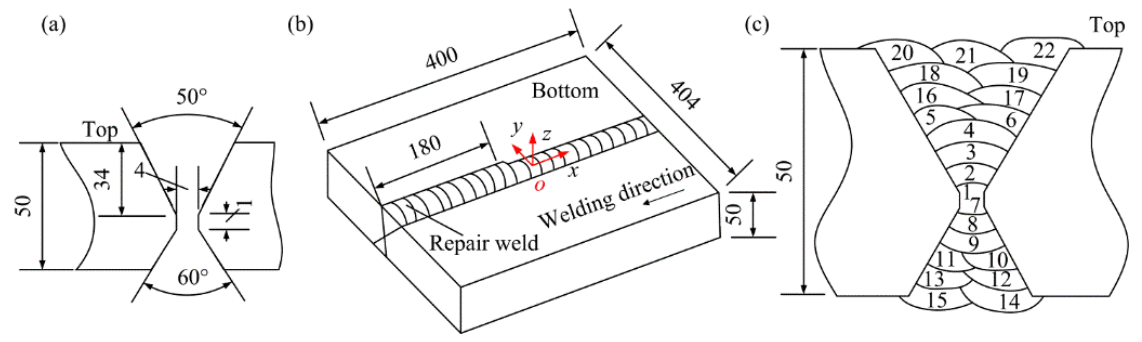

Figure 1. Schematic diagram of the specimen. (a) Groove configuration; (b) dimensions; (c) welding sequence.

(a)

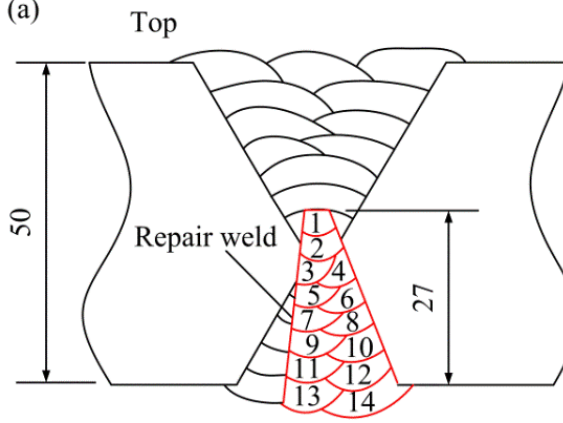

(b)



Figure 2. Welding sequence and dimensions of the repair weld. (a) Welding sequence; (b) dimensions.

Table 2. Welding parameters.

\begin{tabular}{|c|c|c|c|c|}
\hline Weld & Pass Number & Voltage/V & Current/A & Welding Speed $/ \mathrm{mm} \cdot \mathrm{min}^{-1}$ \\
\hline \multirow{4}{*}{ Initial weld } & $1-3$ & $30-32$ & $180-220$ & $188-220$ \\
\hline & $4-13$ & $30-32$ & $230-270$ & $200-300$ \\
\hline & $14-15,20-22$ & $29-30$ & $180-220$ & $180-200$ \\
\hline & $16-19$ & $31-33$ & $240-260$ & $230-300$ \\
\hline \multirow{3}{*}{ Repair weld } & $1-3$ & $30-31$ & $210-250$ & $520-580$ \\
\hline & $4-12$ & $30-31$ & $220-250$ & $250-400$ \\
\hline & $13-14$ & $30-31$ & $220-260$ & $300-330$ \\
\hline
\end{tabular}




\section{Stress Measurement}

\subsection{Three-Cut Contour Method}

While theoretical details for the CM can be found in the reference [10], a summary of implementation of the method is provided here: (1) cutting of the part along the plane-of-interest; (2) measuring the cut surface contours (out-of-plane displacement caused by stress relief); (3) smooth fitting the measured contours to eliminate artefacts and noise introduced by the cutting process; and (4) computing original residual stress using a fully elastic finite element (FE) analysis.

The specimen demonstrated in Figure 1 contains the original weld and a partial repair weld with a length of $180 \mathrm{~mm}$ and a maximum depth of $27 \mathrm{~mm}$. The difference between the stress in the initial weld (as-welded stress) and that in the repair region would be distinguished. In the present study, three cuts were performed sequentially on the specimen and the deformations of the cutting planes were measured, then the stress on the planes can be obtained with the contour method and the superposition-based theory. The schematic diagram of the three cut planes on the specimen are shown in Figure 3. The plane of the first cut locates at the original weld and the second cut plane locates at the middle length of the repair weld, the distance between the first cut plane and the second cut plane is $100 \mathrm{~mm}$. The location of the third cut plane is the weld centerline. The stress normal to the cut plane can be obtained according to the principle of the CM [10], the longitudinal stresses on the planes of the first cut and the second cut, as well as the transverse stress on the plane of the third cut, can be obtained by the CM and the superposition theory, which is explained as follows.

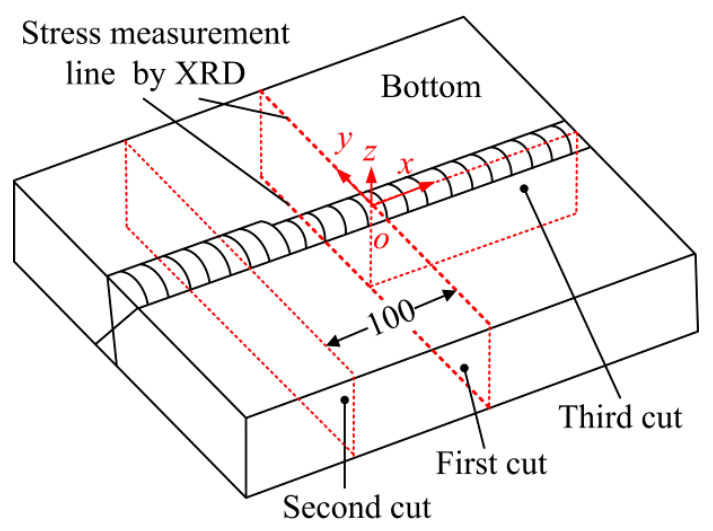

Figure 3. Schematic diagram of the cut planes.

According to Pagliaro et al. [24], the theory for the superposition of stress released by the first cut and that deduced by the second cut to reconstructing the original longitudinal stress on the plane of the second cut is illustrated in Figure 4.

In Figure 4, $\mathbf{A}$ is the intact specimen containing the residual stresses that are to be measured. $\mathbf{B}$ is the half of the specimen with partially-relaxed stresses. $\mathbf{C}$ is the analytical step that starts with a stress-free half part of the specimen and then the surface created by the cut is forced back to its original flat shape. Because the stresses on the cut plane in $\mathbf{B}$ are fully released, the stresses deduced by $\mathbf{C}$ along the plane of the first cut are the original stresses on the first cut plane. Since the measured contour of the cut plane just provides the displacements in the normal direction, only the original longitudinal stress along the first cut plane can be obtained. After the second cut, $\mathbf{D}$ is the quarter-part of the specimen with the residual stress relaxation. $\mathrm{E}$ is the analytical step in which the surface created by the second cut is forced back to its original flat shape, i.e., the stresses in $\mathbf{E}$ are the remaining stresses after the first cut. The stress in $\mathbf{B}$ is given by the superposition of the stress in $\mathbf{D}$ and that in $\mathbf{E}$. The stresses on the cut face in $\mathbf{D}$ are fully released, and the released stressed along the second cut plane caused by the first cut can be deduced by $\mathrm{C}$. Therefore, the sum of $\mathbf{C}$ and $\mathbf{E}$ will give the original stresses along 
the plane of the second cut. As mentioned before, the normal stress component along the second cut plane (part of the original longitudinal stress) can be experimentally determined.

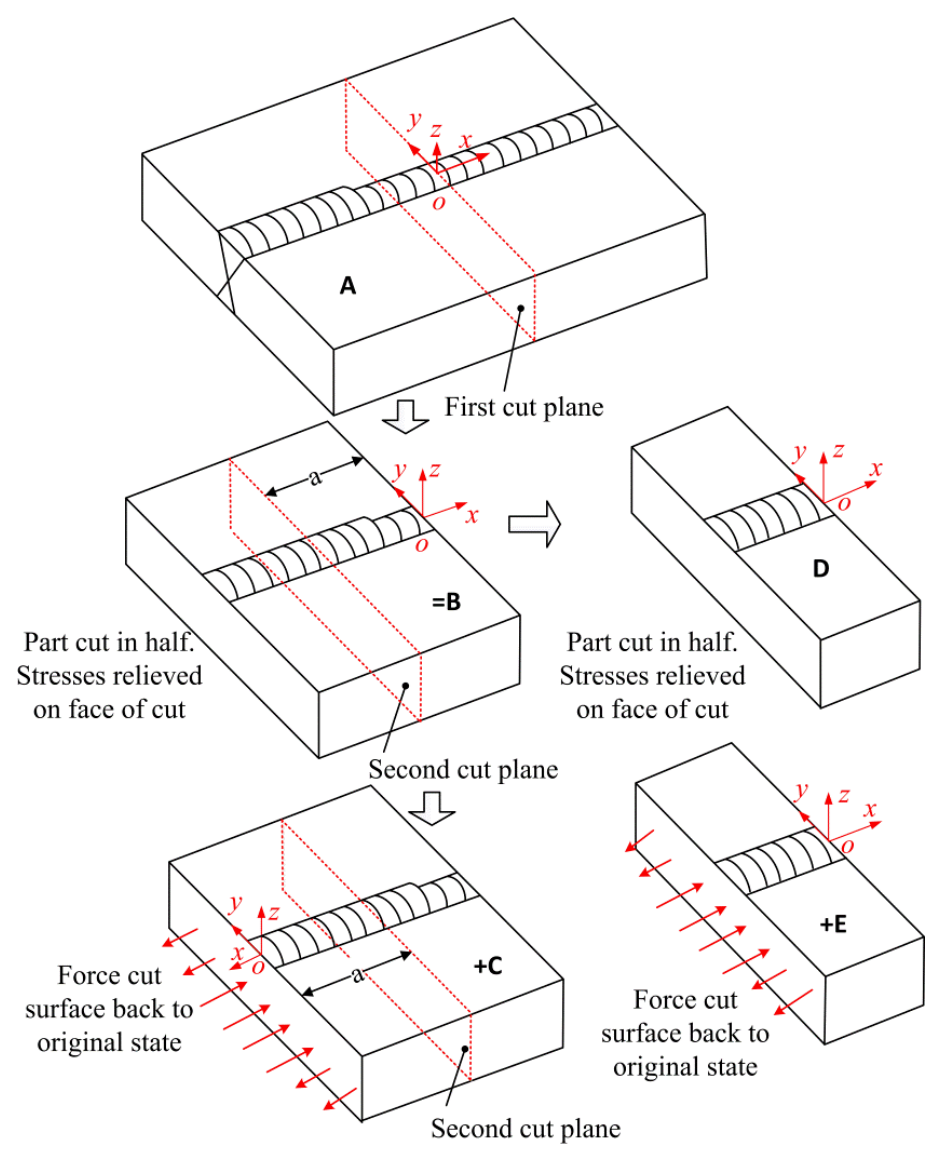

Figure 4. Superposition principle to reconstruct the original stresses on the plane of the second cut.

According to the analysis above, the original longitudinal stresses along the first cut plane and the second cut plane can be expressed as the equations

$$
\begin{gathered}
\sigma_{x}^{(\mathbf{A})}(0, y, z)=\sigma_{x}^{(\mathbf{C})}(0, y, z) \\
\sigma_{x}^{(\mathbf{A})}(-a, y, z)=\sigma_{x}^{(\mathbf{C})}(-a, y, z)+\sigma_{x}^{(\mathbf{E})}(-a, y, z)
\end{gathered}
$$

In the same way, the original stresses along the third cut plane can be obtained by superposing the stresses along the third plane in $\mathbf{C}$ and those on the third cut plane caused by forcing the cut surface back to its original state after the third cut (F), as shown in Figure 5. The deformation in the direction normal to the plane of the third cut can be experimentally measured. Therefore, the normal stress component along the third cut plane-i.e., the transverse stress-can be determined. The original transverse stress on the plane of the third cut can be expressed as the equation

$$
\sigma_{y}^{(\mathbf{A})}(x, 0, z)=\sigma_{y}^{(\mathbf{C})}(x, 0, z)+\sigma_{y}^{(\mathbf{F})}(x, 0, z)
$$

In the present study, each cut was performed on the Sodick ALN400Qs wire electric discharge machine (EDM, Sodick Amoy Co. Ltd., Xiameng, China) with a $250 \mu \mathrm{m}$ diameter brass wire at a nominal cutting speed of $0.12 \mathrm{~mm} / \mathrm{s}$. The specimen was securely clamped onto the worktable of the EDM during cutting with a custom fixture as used in [11]. After cutting, the contours of the cut faces were measured using a Hexagon Global Performance coordinate measuring machine (CMM, Hexagon Metrology (Qingdao) Co. Ltd., Qingdao, China) by measuring the surface height at a grid of in-plane 
locations. For the contour measurement of the cut planes after the first cut, a region consisting of about $80 \mathrm{~mm}$ to either side of the weld center was measured with a point spacing of $1 \mathrm{~mm}$ to better capture the surface profile in the area of expected stress gradients, and other regions were measured with a point spacing of $2 \mathrm{~mm}$. The point spacing for measuring the surfaces of the second cut was also $1 \mathrm{~mm}$. The surface contour data from the two opposite surfaces were carefully aligned and averaged for each cut. Then, the averaged contour was fit to a smooth surface using bivariate splines. The residual stress on the contour plane was found with a linear elastic finite element analysis that applies the smoothed surface profile as a displacement boundary condition on the cut plane. The ANSYS commercial finite element software (Version 16.0, ANSYS Inc., Canonsburg, PA, USA) was used for the modelling and linear elastic static analysis. A geometric model was first built with the dimensions of the after-cut part, and then the eight-node brick elements (Solid185) were used to mesh the model. For the first cut and second cut, node spacing of $1 \mathrm{~mm}$ on the cut face was used and that in the direction normal to the cut face was $2 \mathrm{~mm}$. For the third cut, the node spacing of $2 \times 1 \mathrm{~mm}$ was employed on the cut face and that was $2 \mathrm{~mm}$ in the direction normal to the cut face. To avoid rigid body motion, the model was constrained at two corners of the model with three additional displacement constraints leading to no reaction forces as used in the reference [10]. The model used an elastic modulus of 200 GPa and a Poisson's ratio of 0.30 .



Figure 5. Superposition principle to get the original transverse stress along the plane of the third cut plane.

\subsection{XRD Method}

Before the cut of the contour method, the stress distributions on the top and bottom surfaces were measured by the XRD method to verify the measured results by the contour method. An automated portable diffractiometer (Proto iXRD, Proto Manufacturing Ltd., Oldcastle, Canada) with the $\sin 2 \psi$ method employed. The X-ray was generated from a chromium tube $(20 \mathrm{kV}, 10 \mathrm{~mA})$ with the beam diameter of $1 \mathrm{~mm}$. The diffraction plane was the $\{211\}$ crystallographic plane. The measuring locations of the surface stress are shown in Figure 3.

\section{Results and Discussions}

\subsection{Measured Results by the Contour Method}

Based on the single-cut contour method and the superposition principle of the multi-cut contour method, the residual stress maps at different locations can be obtained, as shown in Figure 6. 
(a)



(b)
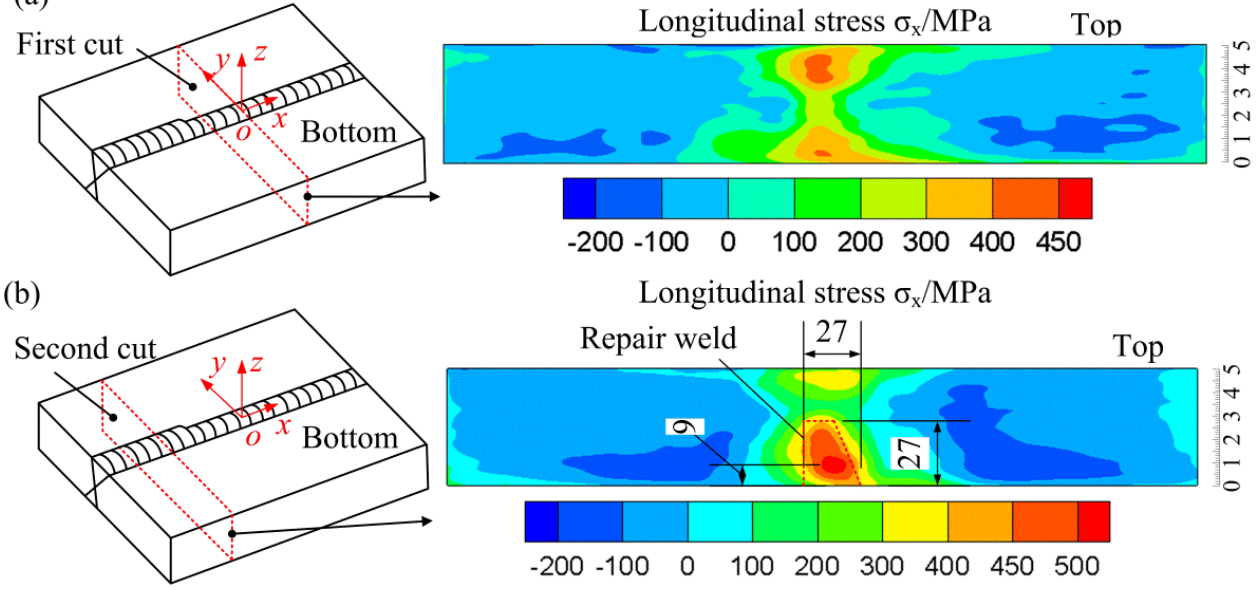

Longitudinal stress $\sigma_{\mathrm{x}} / \mathrm{MPa}$
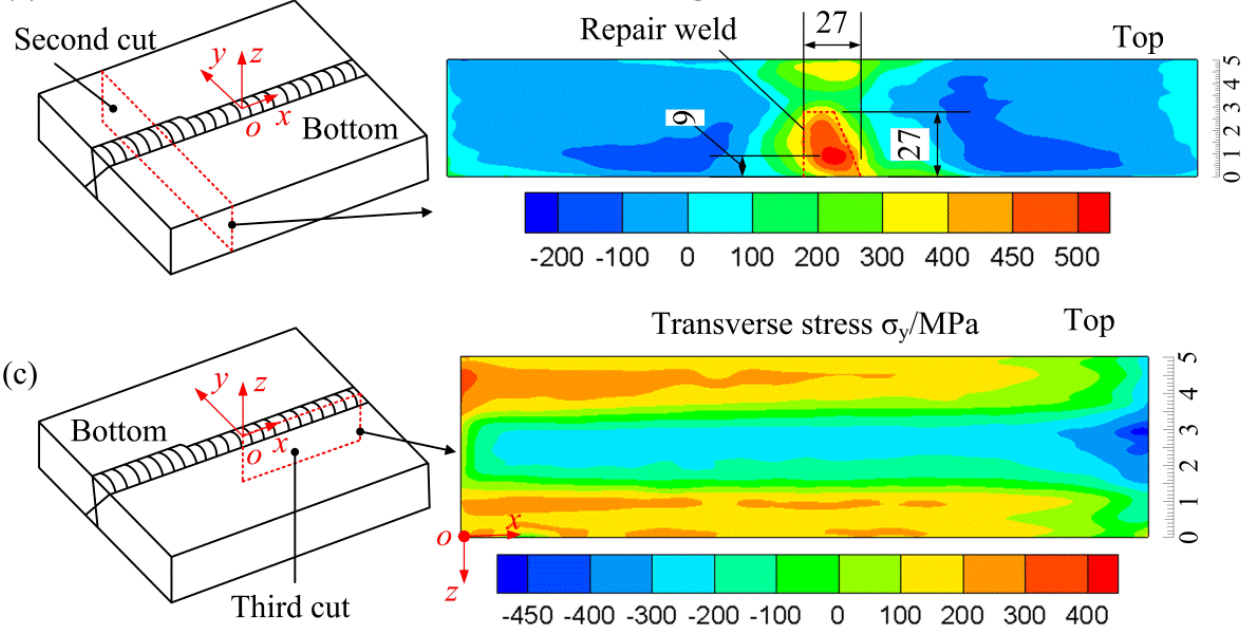

Figure 6. Stress distributions along the three cut planes. (a) Longitudinal stress along the plane of the first cut; (b) longitudinal stress along the plane of the second cut; (c) transverse stress along the plane of the third cut plane.

According to the investigation on the repair weld in the girth weld carried out by George and Smith [7], at a location $25 \mathrm{~mm}$ beyond the end of the repair weld (in the original weld), the hoop residual stress is found to be essentially the same as the as-welded stress as if no repair had been introduced. In the present study, the distance between the end of the repair weld and the first cut plane (within the original weld) is about $20 \mathrm{~mm}$. In addition, the end of the repair weld is very shallow, therefore the longitudinal stress on the first cut plane measured by the CM should not be affected by the repair weld and it should be the as-welded longitudinal stress. Accordingly, the longitudinal stress on the first cut plane (as-welded stress) can be compared with that on the second cut plane (stress after repair) and the difference between them can be investigated.

Figure 6a shows the longitudinal stress on the plane of the first cut (as-welded stress within the original weld). As shown in Figure $6 a$, tensile longitudinal stress is present within the weld zone with small compressive longitudinal stress occurring in the region outside the weld zone to balance the tensile stress in the weld zone (the value of compressive stress ranges from 0 to $-200 \mathrm{MPa}$ ). The longitudinal stress near the top and bottom surfaces is larger than that in the interior. The peak value of the tensile longitudinal stress reaches about $440 \mathrm{MPa}$ appearing at the location about $8 \mathrm{~mm}$ depth beneath the top surface. Near the bottom surface, a maximum longitudinal stress of about $410 \mathrm{MPa}$ is present at the location of $5 \mathrm{~mm}$ depth. Figure $6 \mathrm{~b}$ illustrates the longitudinal stress in the partial repair weld along the plane of the second cut. It shows the similar distribution as that in the initial weld, large tensile longitudinal stress occurs in the weld zone and small compressive stress appears outside. While in the repair weld (the bottom part of the weld zone), the peak longitudinal stress is about $530 \mathrm{MPa}$ occurring at the location of about $9 \mathrm{~mm}$ beneath the bottom surface of the repair weld, which is approximately the yield strength of weld metal at room temperature and it is also larger than that in the original weld at the same location (on the plane of the first cut). Since the repair beads were deposited under strong restraints (the two plates were already welded together), the longitudinal stress increased in the repair region. Compared with Figure 6a, the longitudinal stress 
within the repair weld as a whole in Figure $6 \mathrm{~b}$ is relatively larger than that in the original weld, while the stress in the region above the repair weld is smaller than that in the same region on the plane of the first cut. This is most probably due to the heat treatment effect introduced by the repair weld, which resulted in a stress decrease in the region. From Figure $6 b$, it can be concluded that the introduction of the partial repair weld with a limited depth raises the tensile longitudinal stress in the repair region to a value close to the yield strength and causes a decrease in the longitudinal stress in the region above the repair weld.

Figure $6 \mathrm{c}$ demonstrates the transverse stress distribution at the weld centerline along the plane of the third cut. A distinct self-equilibrated transverse stress distribution is present in the figure with tensile stress occurring towards the top and bottom surfaces and compressive stress presenting in the interior. This kind of stress distribution is the common type of the as-welded transverse at the weld centerline for butt-welded joints by multipass arc welding with the single V groove or double V-type groove as demonstrated by Kartal et al. [25], Liu et al. [11,26], and Smith et al. [27].

\subsection{Comparison of the Results by the Contour Method and XRD Method}

The measured surface stresses by the XRD method are compared with those measured by the CM along the lines on the surfaces and lines with a distance of $2 \mathrm{~mm}$ beneath the surfaces, as shown in Figure 7 .
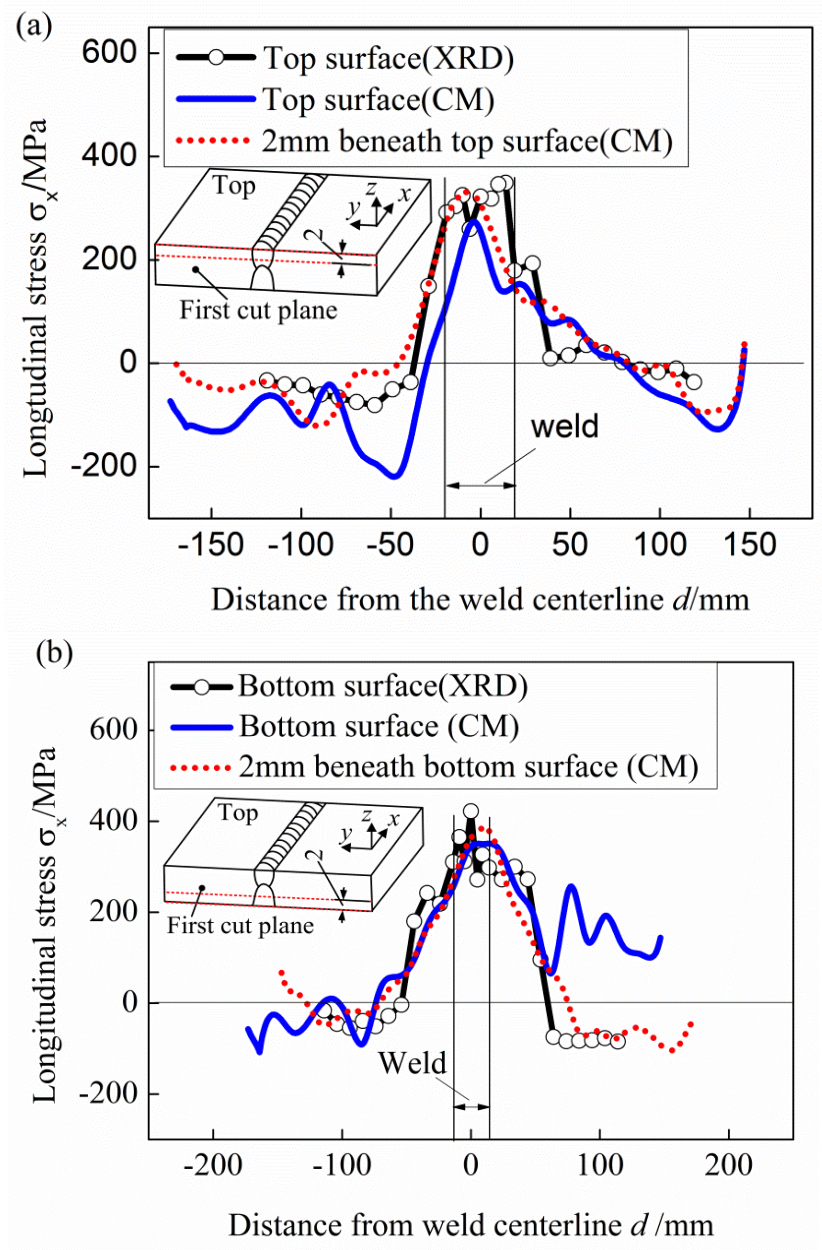

Figure 7. Comparison between the results measured by XRD and CM. (a) Top surface and $2 \mathrm{~mm}$ beneath the top; (b) bottom surface and $2 \mathrm{~mm}$ beneath the bottom surface.

There are additional errors in the displacement measurement near the edges of the cut plane $[10,14,28]$, caused by machining irregularities on the edge and the spherical tip of the CMM 
( $2 \mathrm{~mm}$ in diameter in the present study) going slightly past the actual edge of the part. Therefore, the surface stresses obtained through the CM method are generally less accurate when compared to the XRD. As shown in Figure 7, the discrepancies between the longitudinal stress distribution on the top and bottom surfaces obtained by the CM and the XRD are large, especially on the top surface. However, the stress magnitudes and distributions along the lines with $2 \mathrm{~mm}$ distance beneath the surfaces match quite well with the surface stresses measured by the XRD. Since the change of longitudinal stress within $2 \mathrm{~mm}$-depth surface layer is not significant, it is believed that the measured results obtained by the $\mathrm{CM}$ is reliable and verified by the XRD.

\subsection{Stress Distribution at Different Locations}

To clear analyze the stress distribution on each cut plane, seven lines are selected from the cut planes and the stresses along these lines are compared. The locations of these seven lines are shown in Figure 8. Line L1, line L2, and line L3 are used to evaluate the through-thickness stresses at the weld centerline on the cut planes. Line L4 and line L6 are the lines with a distance of $5 \mathrm{~mm}$ from the top surface of the cut planes, and line L5 and line L7 are those with a distance of $5 \mathrm{~mm}$ from the bottom surface of the cut planes. Uncertainty of CM tends to be larger at the boundaries of the cut planes due to limits on EDM cutting and contour measurement as mentioned before, the line L3 is selected on the plane of the third cut with a distance of $10 \mathrm{~mm}$ from the cut edge.
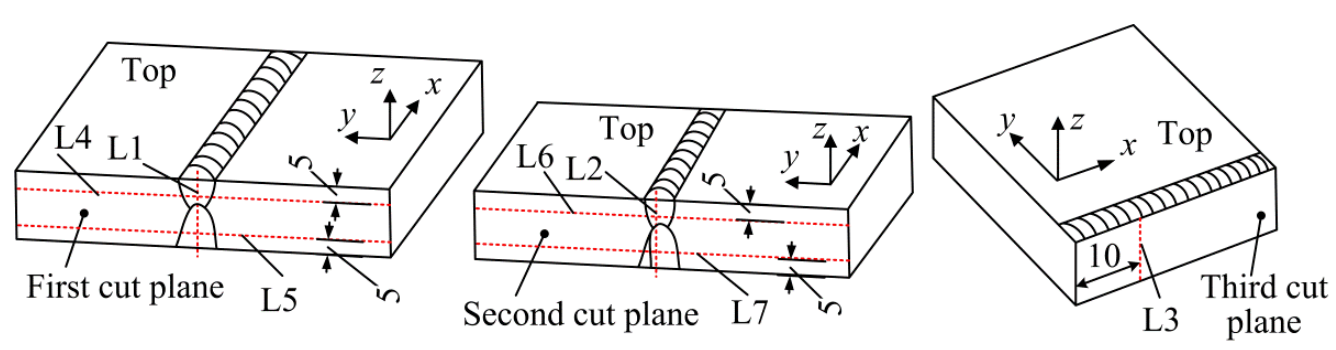

Figure 8. Schematic diagram of the locations of the stress evaluation lines.

Figure 9 shows the stress variations along line L1, line L2, and line L3. The stress along the line L1 is the through-thickness as-welded longitudinal stress at the weld centerline, and that along the line L2 is the through-thickness after-repair longitudinal stress at the weld centerline. From Figure 9, it can be seen that the after-repair longitudinal stress along the thickness at the weld centerline (longitudinal stress along the line L2) decreases within the top region of the weld $(0-20 \mathrm{~mm}$ distance from the top surface) and increases within the repair region ( $0-30 \mathrm{~mm}$ distance from the bottom surface) as compared with the as-welded longitudinal stress (stress along the line L1). The introduction of the repair has increased the peak tensile longitudinal stress in the repair region by $115 \mathrm{MPa}$. For example, the peak tensile stress is about $410 \mathrm{MPa}$ for the original weld near to the bottom surface, and in the repair weld the peak tensile longitudinal stress is raised to about $525 \mathrm{MPa}$. In addition, the peak tensile longitudinal stress in the top region of the original weld beyond the repair is $440 \mathrm{MPa}$, occurring at the location of $14 \mathrm{~mm}$ distance from the top surface (point a in Figure 9), and stress becomes $180 \mathrm{MPa}$ at the same location in the region above the repair (point a' in Figure 9). It means that the maximum longitudinal stress reduction induced by the partial repair in the region above the repair weld can reach $260 \mathrm{MPa}$.

The transverse stress along the thickness in Figure 9 (along Line L3) demonstrates a self-equilibrated distribution, which is tensile towards the top surface, dropping into compression in the central region and returning to tension towards the bottom surface.

The residual stresses are those stresses which are retained within a body when no external forces are acting and therefore they are self-equilibrating inside the free body [1]. The welding residual stress distributions in different directions are completely different as shown in Figure 9. This is caused by the different restraints acting in the directions. Welding residual stresses are mainly generated due to the 
thermal contraction of the weld metal and the adjacent heated parent during cooling. Longitudinal shrinkage of the weld is strongly resisted by the parts being joined, so high tensile residual stresses are generated throughout the thickness of the weld. The longitudinal stress is self-equilibrating along the transverse direction as shown in Figure $6 a, b$. The transverse shrinkage of the final weld passes on the upper and lower surfaces of the plate is resisted by the passes deposited previously, so tensile residual stresses are generated near the upper and lower faces, balanced by compression at mid-thickness, as shown in Figures $6 \mathrm{c}$ and 9.

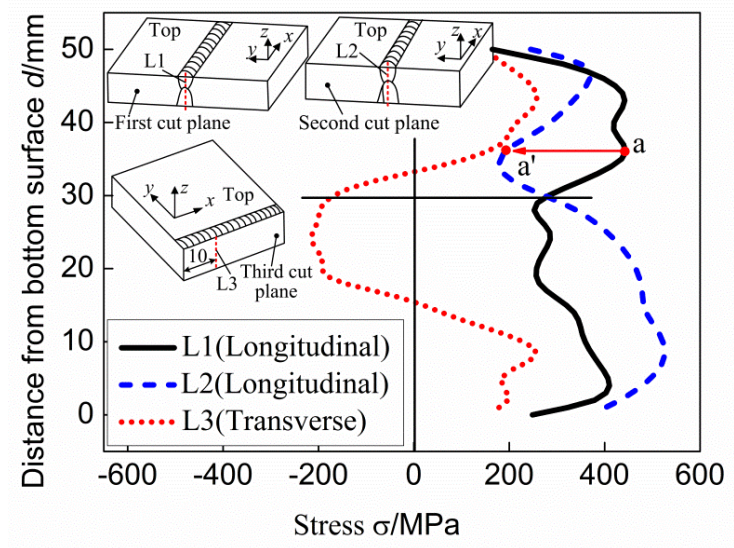

Figure 9. Stress variations along the thickness.

Figure 10 shows the stress variation along lines with $5 \mathrm{~mm}$ distance from the top and bottom surface on different cut planes (in the original weld and the repair weld). As demonstrated in Figure 10a, the longitudinal stress distribution along line L4 (original weld beyond the repair weld near to the top surface) is almost the same as that along line L6 (original weld above the repair weld), except the smaller peak tensile stress along line L6 induced by the repair weld. While the stress distribution along L5 (original weld beyond the repair weld, near to the bottom surface) is a little different from that along line L7 (repair weld near the bottom surface) as demonstrated in Figure 10b, the tensile stress width along line L5 (original weld) is larger than that along line L7 (across repair weld) and the peak tensile longitudinal stress along line L5 is smaller than that along line L7. It can be concluded that the introduction of partial repair weld does not affect the stress distribution trend in the original weld (no matter beyond or above the repair weld), and has slight effect on the tensile stress distribution width in the repair region with significant effect on the peak value of the longitudinal stress in the original weld above the repair weld.
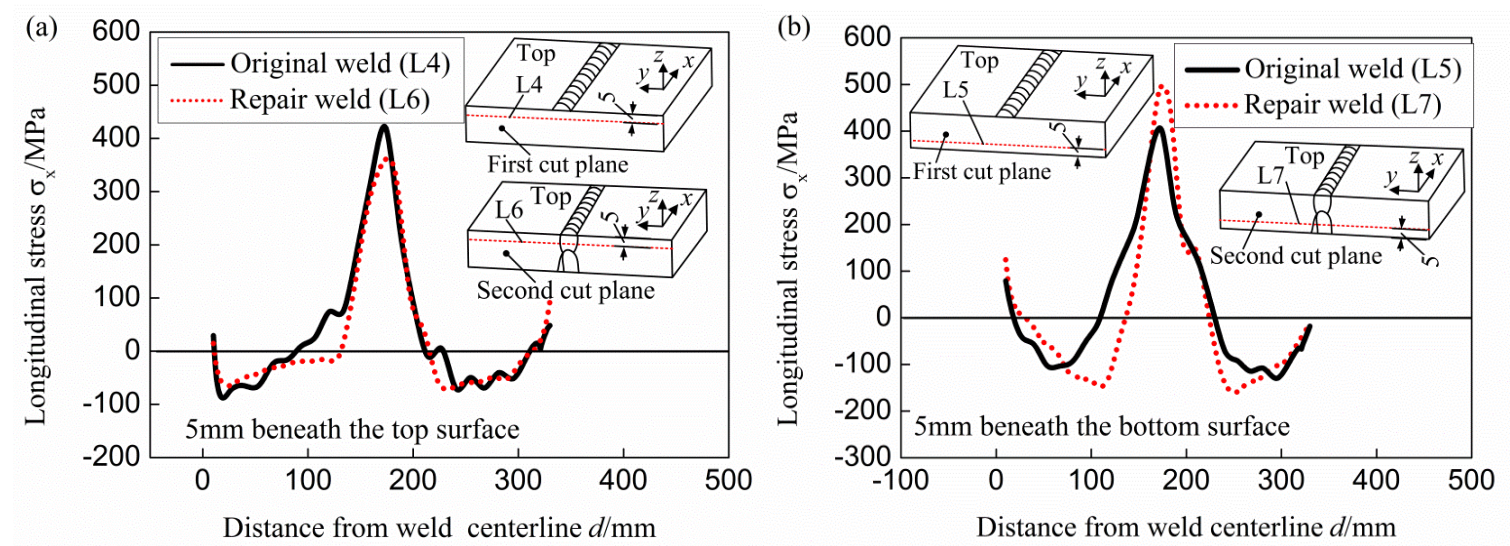

Figure 10. Stress variation along lines with $5 \mathrm{~mm}$ distance from the top and bottom surfaces. (a) Near the top surface; (b) near the bottom surface. 


\section{Conclusions}

The stress distributions in a thick welded specimen with a partial repair weld were measured with the three-cut contour method. The longitudinal stress maps in the original weld and the repair weld were obtained and the transverse stress map at the weld centerline in the original weld was also acquired. The variation of the longitudinal stress before and after the repair was investigated. The main findings can be concluded as follows:

(1) The contour method with multiple cuts based on the superposition principle can be used to get stress distribution maps at different cut locations. The measured longitudinal stress through the $\mathrm{CM}$ along the lines with $2 \mathrm{~mm}$ distance beneath the top and bottom surfaces can be verified by the surface stress measured by XRD.

(2) The partial repair weld has a great effect on the magnitude of as-welded longitudinal stress in the repair region and the region above the repair. Comparing with the stress in the original weld, the longitudinal stress increases significantly throughout the entire repair region and that decreases distinctly in the region above the repair weld due to the heat treatment effect.

(3) The introduction of the repair weld raises the peak through-thickness longitudinal stress by about $115 \mathrm{MPa}$ at the weld centerline in the present study, resulting in a peak tensile longitudinal stress close to the yield strength of weld material at room temperature. A maximum longitudinal stress reduction of about $260 \mathrm{MPa}$ is induced by the repair weld in the region above the repair weld in the present study.

(4) The introduction of partial repair weld does not affect the stress distribution trend in the original weld (whether it is beyond or above the repair weld), and it has slight effect on the tensile stress distribution width in the repair region.

Acknowledgments: This work is supported by the National Natural Science Foundation of China (no. 51575251).

Author Contributions: Chuan Liu conceived and designed the experiemnts, and also wrote the paper; Chunjing Wang, Xiaohua Cheng, Yi Yan, and Jiawei Yang performed the experiments; Xiaohua Cheng contributed materials; Yuhang Guo contributed the measurement tools and analyzed the data.

Conflicts of Interest: The authors declare no conflict of interest.

\section{References}

1. Withers, P.J. Residual stress and its role in failure. Rep. Prog. Phys. 2007, 70, 2211-2264. [CrossRef]

2. Dong, P.; Zhang, J.; Bouchard, P.J. Effects of repair weld length on residual stress distribution. J. Press. Vessel. Technol. 2002, 124, 74-80. [CrossRef]

3. Dong, P.; Hong, J.K.; Bouchard, P.J. Analysis of residual stresses at weld repairs. Int. J. Press. Vessel. Pip. 2005, 82, 258-269. [CrossRef]

4. Song, S.; Dong, P. Residual stresses at weld repairs and effects of repair geometry. Sci. Technol. Weld. Join. 2017, 22, 265-277. [CrossRef]

5. Zeinoddini, M.; Arnavaz, S.; Zandi, A.P.; Vaghasloo, Y.A. Repair welding influence on offshore pipelines residual stress fields: An experimental study. J. Constr. Steel Res. 2013, 86, 31-41. [CrossRef]

6. Veiga, C.; Loureiro, A.; Dias, A. Residual stress evolution in repair welds. Strain 2003, 39, 57-63. [CrossRef]

7. George, D.; Smith, D.J. Through thickness measurement of residual stresses in a stainless steel cylinder containing shallow and deep weld repairs. Int. J. Press. Vessel. Pip. 2005, 82, 279-287. [CrossRef]

8. Bouchard, P.J.; George, D.; Santisteban, J.R.; Bruno, G.; Dutta, M.; Edwards, L.; Kingston, E.; Smith, D.J. Measurement of the residual stresses in a stainless steel pipe girth weld containing long and short repairs. Int. J. Press. Vessel. Pip. 2005, 82, 299-310. [CrossRef]

9. Muránsky, O.; Hosseinzadeh, F.; Hamelin, C.J.; Traore, Y.; Bendeich, P.J. Investigating optimal cutting configurations for the contour method of weld residual stress measurement. Int. J. Press. Vessel. Pip. 2017, in press. [CrossRef]

10. Prime, M.B. Cross-sectional mapping of residual stresses by measuring the surface contour after a cut. J. Eng. Mater. Technol. 2001, 123, 162-168. [CrossRef] 
11. Liu, C.; Chen, D.J.; Hill, M.R.; Tran, M.N.; Zou, J.S. Effects of ultrasonic impact treatment on weld microstructure, hardness, and residual stress. Mater. Sci. Technol. 2017, 33, 1601-1609. [CrossRef]

12. Zhang, Y.; Ganguly, S.; Edwards, L.; Fitzpatrick, M.E. Cross-sectional mapping of residual stresses in a VPPA weld using the contour method. Acta Mater. 2004, 52, 5225-5232. [CrossRef]

13. Liu, C.; Zhu, H.Y.; Dong, C.L. Internal residual stress measurement on inertia friction welding of nickel-based superalloy. Sci. Technol. Weld. Join. 2014, 19, 408-415. [CrossRef]

14. Richter-Trummer, V.; Suzano, E.; Beltrão, M.; Roos, A.; dos Santos, J.F.; de Castro, P.M.S.T. Influence of the FSW clamping force on the final distortion and residual stress field. Mater. Sci. Eng. A 2012, 538, 81-88. [CrossRef]

15. Sun, T.Z.; Roy, M.J.; Strong, D.; Withers, P.J.; Prangnell, P.B. Comparison of residual stress distributions in conventional and stationary shoulder high-strength aluminum alloy friction stir welds. J. Mater. Process. Technol. 2017, 242, 92-100. [CrossRef]

16. Smith, M.; Levesque, J.-B.; Bichler, L.; Sediako, D.; Gholipour, J.; Wanjara, P. Residual stress analysis in linear friction welded in-service Inconel 718 superalloy via neutron diffraction and contour method approaches. Mater. Sci. Eng. A 2017, 691, 168-179. [CrossRef]

17. Xie, P.; Zhao, H.; Wu, B.; Gong, S. Evaluation of residual stresses relaxation by post weld heat treatment using contour method and X-ray diffraction method. Exp. Mech. 2015, 55, 1329-1337. [CrossRef]

18. Frankel, P.; Preuss, M.; Steuwer, A.; Withers, P.J.; Bray, S. Comparison of residual stresses in Ti-6Al-4V and Ti6Al-2Sn-4Zr-2Mo linear friction welds. Mater. Sci. Technol. 2009, 25, 640-650. [CrossRef]

19. Braga, D.F.O.; Coules, H.E.; Pirling, T.; Richter-Trummer, V.; Colegrove, P.; de Castro, P.M.S.T. Assessment of residual stress of welded structural steel plates with or without post weld rolling using the contour method and neutron diffraction. J. Mater. Process. Technol. 2013, 213, 2323-2328. [CrossRef]

20. Woo, W.; An, G.B.; Kingston, E.J.; DeWald, A.T.; Smith, D.J.; Hill, M.R. Through-thickness distributions of residual stresses in two extreme heat-input thick welds: A neutron diffraction, contour method and deep hole drilling study. Acta Mater. 2013, 61, 3564-3574. [CrossRef]

21. Olson, M.D.; Hill, M.R. A new mechanical method for biaxial residual stress mapping. Exp. Mech. 2015, 55, 1139-1150. [CrossRef]

22. Pagliaro, P.; Prime, M.B.; Robinson, J.S.; Clausen, B.; Swenson, H.; Steinzig, M.; Zuccarello, B. Measuring inaccessible residual stresses using multiple methods and superposition. Exp. Mech. 2011, 51, 1123-1134. [CrossRef]

23. Hosseinzadeh, F.; Bouchard, P.J. Mapping multiple components of the residual stress tensor in a large P91 steel pipe girth weld using a single contour cut. Exp. Mech. 2013, 53, 171-181. [CrossRef]

24. Pagliaro, P.; Prime, M.B.; Swenson, H.; Zuccarello, B. Measuring multiple residual-stress components using the contour method and multiple cuts. Exp. Mech. 2010, 50, 187-194. [CrossRef]

25. Kartal, M.E.; Kang, Y-H.; Korsunsky, A.M.; Cocks, A.C.F.; Bouchard, J.P. The influence of welding procedure and plate geometry on residual stresses in thick components. Int. J. Solids Struct. 2016, 80, 420-429. [CrossRef]

26. Liu, C.; Ge, Q.L.; Chen, D.J.; Gao, F.; Zou, J.S. Residual stress variation in a thick welded joint after ultrasonic impact treatment. Sci. Technol. Weld. Join. 2016, 21, 624-631. [CrossRef]

27. Smith, D.J.; Bouchard, P.J.; George, D. Measurement and prediction residual stress in thick section steel welds. J. Strain Anal. Eng. Des. 2000, 35, 287-305. [CrossRef]

28. Hatamleh, O.; DeWald, A. An investigation of the peening effects on the residual stresses in friction stir welded 2195 and 7075 aluminum alloy joints. J. Mater. Process. Technol. 2009, 209, 4822-4829. [CrossRef]

(C) 2018 by the authors. Licensee MDPI, Basel, Switzerland. This article is an open access article distributed under the terms and conditions of the Creative Commons Attribution (CC BY) license (http:/ / creativecommons.org/licenses/by/4.0/). 